\title{
Exigência de fósforo disponível para juvenis de tilápia-do-nilo
}

\section{Wilson Massamitu Furuya ${ }^{1}$, Keila Michele Fujii², Lílian Dena dos Santos ${ }^{3}$, Tarcila Souza de Castro Silva ${ }^{3}$, Lilian Carolina Rosa da Silva ${ }^{3}$, Priscila Juliana Pinseta Sales ${ }^{2}$}

\author{
${ }^{1}$ Departamento de Zootecnia, UEM, Av. Colombo, 5790, CEP: 87020-900, Maringá-PR. \\ 2 Curso de Graduação em Zootecnia - UEM, Maringá-PR. \\ 3 Programa de Pós-Graduação em Zootecnia - UEM, Maringá-PR.
}

RESUMO - Determinou-se a exigência de fósforo disponível para juvenis de tilápia-do-nilo. Utilizou-se delineamento em blocos inteiramente casualisados com quatro tratamentos e quatro repetições. Foram fornecidas manualmente, durante 120 dias, dietas com $32 \%$ de proteína bruta e $3.050 \mathrm{kcal}$ de energia digestível $/ \mathrm{kg}$, suplementadas com fosfato bicálcico de forma a se obterem 0,$21 ; 0,40 ; 0,56$ e $0,71 \%$ de fósforo disponível. Não houve efeito dos níveis de fósforo da dieta sobre o consumo, os teores de proteína e extrato etéreo na carcaça e a taxa de mortalidade. Os níveis de proteína e energia digestível tiveram efeito quadrático sobre o ganho de peso, a conversão alimentar, a taxa de eficiência protéica e a porcentagem de cálcio nos ossos, que foram melhores nos níveis 0,55; 0,52; 0,52 e 0,60\% de fósforo disponível, respectivamente. Pela análise dos dados pelo modelo de regressão "broken-line”, obteve-se adequada retenção de fósforo nos ossos com 0,64\% desse mineral na dieta. A exigência de fósforo disponível para juvenis de tilápia-do-nilo é de 0,52\%.

Palavras-chave: desempenho, exigência, fósforo disponível, minerais nos ossos, Oreochromis niloticus, tilápia-do-nilo

\section{Available phosphorus requirements of juvenile Nile tilapia}

ABSTRACT - Available phosphorus requirement of juvenile Nile tilapia (Oreochromis niloticus) was determined. A total of 352 fishes with initial weight of $0.41 \mathrm{~g} \pm 0.30 \mathrm{~g}$ was assigned to a completely block experimental design were used, with four levels of available phosphorus and four replications. Diets with 32.0\% CP and 3,050 kcal DE $/ \mathrm{kg}$ were supplemented with dicalcium phosphate to obtain levels of $0.21 ; 0.40 ; 0.56$ and $0.71 \%$ of available phosphorus in the diets. Diets were handly fed during 120 days. No effects of available phosphorus levels on feed intake, content of protein and ether extract in the carcass and mortality rate were observed. The available phosphorus levels showed a quadratic effect on weight gain, feed:gain ratio, protein efficiency ratio and the calcium percentage in the bones, that were better in levels $0.55,0.52,0.52$, and $0.60 \%$ of available phosphorus, respectively. Data analysis by broken-line regression method indicated adequate deposition of phosphorus in the bone with $0.64 \%$ of phosphorus in the diet. The requirement of available phosphorus for juvenile Nile tilapia raised in recirculation tanks is of $0.52 \%$.

Key Words: available phosphorus, bone minerals, Nile tilapia, Oreochromis niloticus, performance, requirements

\section{Introdução}

A tilápia-do-nilo (Oreochromis niloticus) é uma das espécies mais utilizadas em criações intensivas no Brasil. É considerada a espécie mais promissora para a piscicultura, em virtude do rápido crescimento em cativeiro e por possuir carne de boa qualidade.

O fósforo é um macromineral essencial para o adequado crescimento e a reprodução dos peixes, importante constituinte estrutural do tecido esquelético (Roy \& Lall, 2003) e que também se encontra distribuído em todas as células do organismo, portanto, exigido em grandes quantidades na dieta (Lovell, 1988).
A deficiência de fósforo resulta em menor mineralização dos ossos (Furuya et al., 2001a), redução na taxa de crescimento e deposição de minerais na carcaça e nos ossos (Dougall et al., 1996; Hardy \& Glatin III, 2002; Lall, 2002). Peixes alimentados com rações deficientes em fósforo apresentam deformidades em diversas regiões do corpo (Cheng et al., 2005), como resultado da dificuldade na mineralização, que resulta em ossos porosos (Sugiura et al., 2004). O aumento na deposição de lipídios na carcaça também tem sido observado, provavelmente em razão da alteração nos níveis plasmáticos de fosfatase alcalina e de enzimas envolvidas na gliconeogênese no fígado (Baeverfjord et al., 1998; Zhang et al., 2006; Yang et al., 2006). 
As exigências de fósforo total pelos peixes variam de 0, 24 a 1,2\% (NRC, 1993; Asgard, 1977; Shearer, 1997). O adequado balanceamento de minerais é importante por diminuir as perdas urinária e fecal e reduzir a possibilidade de eutrofização (Richie \& Brown, 1996), que pode comprometer a qualidade da água e as características organolépticas da carcaça dos peixes (Van Der Ploeg \& Boyd, 1991).

Apesar de os peixes poderem absorver o fósforo da água, a capacidade de utilização desse mineral é reduzida. Além disso, a concentração desse elemento geralmente é baixa em água doce, o que torna a dieta a principal fonte desse mineral, (Roy \& Lall, 2003).

Ainda são poucos os trabalhos realizados no Brasil objetivando determinar as exigências de fósforo de tilápias-do-nilo em criação intensiva nas diversas fases de criação. Esses estudos são necessários para aumentar o desempenho produtivo de forma economicamente viável, com adequado crescimento dos peixes e manutenção da qualidade de carcaça e da qualidade da água, o que permite a criação sustentável de tilápias em criações intensivas.

Este trabalho foi realizado com o objetivo de determinar a exigência de fósforo disponível para juvenis de tilápia-donilo em tanques de recirculação de água.

\section{Material e Métodos}

O experimento foi realizado no Laboratório de Aqüicultura da Universidade Estadual de Maringá - UEM, Maringá, Paraná, durante o período dezembro de 2004 a março de 2005, durante 120 dias.

Foram utilizados 352 peixes sexualmente revertidos durante a fase larval, com peso inicial de $0,41 \pm 0,30 \mathrm{~g}$. Os peixes foram distribuídos em 16 gaiolas circulares $\left(0,2 \mathrm{~m}^{3}\right)$ distribuídas em quatro tanques $\left(1 \mathrm{~m}^{3}\right)$ de fibrocimento, cada um com uma unidade experimental de cada tratamento. Os tanques foram mantidos em sistema de recirculação da água (7 vezes/dia), com aeração individual por meio de pedra porosa acoplada a um soprador central, oxigênio dissolvido entre 4 e $6 \mathrm{mg} / \mathrm{L}$ por meio de pedra porosa e temperatura de 28 a $30^{\circ} \mathrm{C}$, controlada por meio de aquecedores ligados a um termostato.

Foram elaboradas quatro dietas com aproximadamente $3.050 \mathrm{kcal}$ de energia digestível $/ \mathrm{kg}$, 32\% de proteína bruta e 30\% de proteína digestível para atender às exigências descritas pelo NRC (1993) para tilápias. As dietas diferiram apenas quanto aos níveis de fosfato bicálcico: 0,21; 0,40; 0,56 e $0,71 \%$ de fósforo disponível (Tabela 1 ).

$\mathrm{O}$ arraçoamento foi realizado seis vezes ao dia, às $8 \mathrm{~h}$; 8h30; $13 \mathrm{~h} ; 13 \mathrm{~h} 30 ; 17 \mathrm{~h}$ e $17 \mathrm{~h} 30$, manualmente e até saciedade aparente. Todos os ingredientes foram triturados em
Tabela 1 - Composição das dietas experimentais

\begin{tabular}{|c|c|c|c|c|}
\hline \multirow[b]{2}{*}{ Ingrediente } & \multicolumn{4}{|c|}{ Fósforo disponível (\%) } \\
\hline & 0,21 & 0,40 & 0,56 & 0,71 \\
\hline Quirera de arroz & 33,35 & 32,70 & 32,10 & 31,50 \\
\hline Farelo de soja & 50,00 & 50,00 & 50,00 & 50,00 \\
\hline Glúten de milho 60 & 9,00 & 9,00 & 9,00 & 9,00 \\
\hline Farinha de peixe & 3,00 & 3,00 & 3,00 & 3,00 \\
\hline Calcário calcítico & 1,45 & 0,90 & 0,40 & 0,00 \\
\hline Fosfato bicálcico & 0,00 & 1,00 & 1,90 & 2,70 \\
\hline Óleo de soja & 2,00 & 2,20 & 2,40 & 2,60 \\
\hline L-lisina & 0,10 & 0,10 & 0,10 & 0,10 \\
\hline DL-metionina & 0,10 & 0,10 & 0,10 & 0,10 \\
\hline L-treonina & 0,10 & 0,10 & 0,10 & 0,10 \\
\hline $\begin{array}{l}\text { Suplemento mineral e } \\
\text { vitamínico }{ }^{1}\end{array}$ & 0,50 & 0,50 & 0,50 & 0,50 \\
\hline Vitamina $C^{2}$ & 0,05 & 0,05 & 0,05 & 0,05 \\
\hline Sal comum & 0,35 & 0,35 & 0,35 & 0,35 \\
\hline $\mathrm{BHT}^{3}$ & 0,02 & 0,02 & 0,02 & 0,02 \\
\hline Matéria seca $(\%)^{4}$ & 88,66 & 88,71 & 88,81 & 88,87 \\
\hline $\begin{array}{l}\text { Energia digestível } \\
(\mathrm{kcal} / \mathrm{kg})^{5}\end{array}$ & 3.052 & 3.055 & 3.049 & 3.048 \\
\hline Proteína bruta $(\%)^{4}$ & 32,11 & 31,88 & 32,17 & 32,33 \\
\hline Fibra bruta $(\%)^{4}$ & 4,05 & 4,16 & 4,15 & 4,14 \\
\hline Extrato etéreo $(\%)^{4}$ & 4,42 & 4,69 & 4,78 & 4,95 \\
\hline Cálcio $(\%)^{4}$ & 0,90 & 0,91 & 0,92 & 0,95 \\
\hline Fósforo disponível $(\%)^{5}$ & 0,21 & 0,40 & 0,56 & 0,71 \\
\hline
\end{tabular}

${ }^{1}$ Suplemento mineral e vitamínico (Supre Mais): composição por kg vit. A - 1200.000 UI; vit. D3 - 200.000 UI; vit. E - 12.000 mg; vit. K3 $2.400 \mathrm{mg}$; vit. B1 - $4.800 \mathrm{mg}$; vit. B2 - $4.800 \mathrm{mg}$; vit. B6 - $4.000 \mathrm{mg}$; vit. B12 - $4.800 \mathrm{mg}$; ác. fólico - $1.200 \mathrm{mg}$; pantotenato de cálcio $-12.000 \mathrm{mg}$ vit. C - $48.000 \mathrm{mg}$; biotina - $48 \mathrm{mg}$; colina - $65.000 \mathrm{mg}$; niacina - $24.000 \mathrm{mg}$; $\mathrm{Fe}-10.000 \mathrm{mg} ; \mathrm{Cu}-600$ mg; Mg - 4.000 mg; Zn - 6.000 mg; I 20 mg; Co - $2 \mathrm{mg}$; Se - $20 \mathrm{mg}$.

2 Vitamina C: (42\% de ácido ascórbico).

3 Butil Hidroxi Tolueno.

${ }^{4}$ Valores determinados no Laboratório de Análises de Alimentos do Departamento de Zootecnia da Universidade Estadual de Maringá, Maringá-PR.

${ }^{5}$ De acordo com valores coeficientes de digestibilidade obtidos neste trabalho.

moinho martelo elétrico até atingirem diâmetro igual ou inferior a 0,36 mm. As rações foram extrusadas na Fazenda Experimental de Iguatemi(FEI) de forma a se obterem grânulos com diâmetro médio de 3,5 mm. Durante os primeiros 30 dias do experimento, a ração foi desintegrada em liquidificador e peneirada até que os grânulos apresentassem diâmetro médio de $0,25 \mathrm{~mm}$. Todos os peixes foram pesados ao início e final do experimento.

Ao final do experimento, o osso submandibular da cabeça e todos os ossos da coluna vertebral de todos os peixes de cada unidade experimental foram moídos e desengordurados (soxlet) para análise da retenção de cálcio e fósforo nos ossos. A coleta dos ossos para determinação das concentrações desses minerais foi realizada segundo metodologia descrita por Furuya et al. (2001b).

Os valores de energia digestível e fósforo disponível das dietas foram obtidos pela determinação dos coeficientes de digestibilidade, de acordo com a expressão descrita por Nose (1960): 


$$
C D A=100-\left[100 \cdot\left(\frac{\% I_{d}}{\% I_{f}}\right) \cdot\left(\frac{\% P_{f}}{\% P_{d}}\right)\right]
$$

em que: $\mathrm{CDA}$ = coeficiente de digestibilidade aparente (\%); $\% \mathrm{I}_{\mathrm{d}}$ e $\% \mathrm{I}_{\mathrm{f}}=$ porcentagem indicador na dieta e nas fezes, respectivamente; $\% \mathrm{P}_{\mathrm{f}} \mathrm{e} \% \mathrm{P}_{\mathrm{d}}=$ porcentagem de fósforo nas fezes e na dieta, respectivamente.

O óxido de cromo (III) foi utilizado como indicador $(0,1 \%$ da dieta). As dietas experimentais utilizadas no estudo de desempenho produtivo foram moídas, com pulverização de água $\left(55^{\circ} \mathrm{C}\right)$ na proporção de $12 \%$ de seu peso total peletizadas em moinho de carne e desidratadas em estufa de ventilação forçada $\left(55^{\circ} \mathrm{C}\right)$, durante 18 horas (Pezzato el al., 2002). A coleta de fezes foi realizada diariamente às $8 \mathrm{~h}$ e $17 \mathrm{~h}$, durante sete dias, para formar um pool de amostra considerado repetição. Para cada ração analisada, foram coletados três pools de fezes.

Para troca de dieta, foi estabelecido um intervalo de cinco dias para adaptação. O material coletado foi desidratado em estufa de ventilação forçada a $55^{\circ} \mathrm{C}$ durante 24 horas. Após secagem, o material foi triturado em moinho martelo, identificado e armazenado em refrigerador para posterior análise.

Os peixes foram alimentados a cada 2 horas, das 8 às $17 \mathrm{~h}$, manualmente e até saciedade aparente, quando não era observada captura dos grânulos fornecidos durante o deslocamento dos peixes da superfície até o fundo dos aquários de alimentação.

As análises químicas das dietas, das carcaças e dos ossos foram realizadas no Laboratório de Análise de Alimentos do Departamento da Universidade Estadual de Maringá - UEM, segundo metodologia descrita por Silva \& Queiroz (2002). A análise do óxido de cromo (III) foi realizada de acordo com metodologia descrita por Bremer-Neto et al. (2005).

Os dados foram submetidos a análises de variância e regressão polinomial ou broken-line por meio do pacote estatístico SAS (2000).

\section{Resultados e Discussão}

Não foram observados efeitos $(\mathrm{P}>0,05)$ dos níveis de fósforo disponível sobre o consumo de ração e a taxa de mortalidade (Tabela 2). Neste estudo, após 120 dias de experimento, não foram observados sinais externos de anormalidades ou deformidades ósseas durante a coleta de ossos para análise de minerais. As deformidades esqueléticas são os principais sintomas de deficiências morfopatológicas em peixes alimentados com dietas deficientes em fósforo (Lall, 2002; Sugiura et al., 2004).

Yang et al. (2006) não observaram sinais de anormalidades externas em peixes alimentados durante 56 dias com dietas deficientes em fósforo, logo, o surgimento dos sintomas de deficiência de fósforo está relacionado à duração do experimento, uma vez que Cheng et al. (2005) observaram deformidades ósseas na região da cabeça de juvenis de Epinephelus malabaricus alimentados com dietas contendo $0,26 \%$ de fósforo disponível (0,23\% na matéria natural). A apresentação dos valores com base na matéria seca (MS) é necessária para comparação dos dados descritos em periódicos estrangeiros. Segundo Roy \& Lall (2003), a severidade da deficiência de fósforo varia com a duração do experimento, mas pode ser influenciada por diversos fatores relacionados à água, ao peixe e à dieta utilizada.

Os resultados obtidos neste estudo corroboram os encontrados por Oliva-Teles \& Pimentel-Rodrigues (2004) em estudos com sea bass europeu (Dicentrarchus labrax). Esses autores também não observaram efeitos da utilização de 0,$48 ; 0,65 ; 0,77 ; 0,86 ; 1,05$ e 1,25\% de fósforo total (base na MS) sobre o consumo de ração. No entanto, neste estudo, houve redução no consumo pelos peixes alimentados com a dieta com menor valor de fósforo disponível, fato constatado também por Yang et al. (2006) em estudo com juvenis de milkfish (Chanos chanos).

O aumento nos níveis de fósforo disponível teve efeito quadrático $(\mathrm{P}<0,05)$ sobre o ganho de peso, a conversão

Tabela 2 - Desempenho de juvenis de tilápia-do-nilo alimentados com dietas contendo diferentes níveis de fósforo disponível

\begin{tabular}{|c|c|c|c|c|c|}
\hline Peso inicial (g) & 0,42 & 0,41 & 0,41 & 0,41 & 7,53 \\
\hline Peso final (g) & 25,04 & 36,13 & 38,51 & 35,62 & 6,87 \\
\hline Ganho de peso $(\mathrm{g})^{2}$ & 24,62 & 35,72 & 38,10 & 35,21 & 6,92 \\
\hline Consumo (g/peixe) & 41,34 & 48,47 & 45,33 & 50,42 & 13,68 \\
\hline Conversão alimentar ${ }^{2}$ & 1,67 & 1,36 & 1,19 & 1,43 & 10,70 \\
\hline
\end{tabular}

${ }^{1} \mathrm{CV}=$ coeficiente de variação.

2 Efeito quadrático: ganho de peso: $P<0,05): Y=2,607+129,796 X-118,222 X^{2} ; R^{2}=0,99$; conversão alimentar $(P<0,05): Y=2,514-4,928 X+4,755 X^{2}$; $R^{2}=0,98 ;(P<0,05)$; taxa de eficiência protéica $(P<0,05): Y=0,682+8,504 X-8,187 X^{2} ; R^{2}=0,88$. 
alimentar e a taxa de eficiência protéica. Os melhores valores dessas variáveis foram obtidos com 0,55; 0,52 e $0,52 \%$ de fósforo disponível na matéria natural, respectivamente, que correspondem a 0,62; 0,59 e 0,59\% de fósforo disponível na MS.

Pimentel-Rodrigues \& Oliva-Teles (2001), em trabalho realizado com juvenis de gilthead sea bream (Sparus aurata), observaram pequeno aumento no ganho de peso e melhora na conversão alimentar de peixes alimentados com dietas contendo mais de $0,75 \%$ de fósforo total na MS, no entanto, não observaram piora no crescimento ou na eficiência de utilização do fósforo pelos peixes alimentados dietas com até 1,7\% de fósforo total na MS, o que também foi confirmado por Asgard \& Shearer (1997) em estudo realizado com juvenis de salmão-do-atlântico (Salmo salar) alimentados com dietas contendo 0,44 a 2,53\% de fósforo na MS.

O menor ganho de peso e a piora na conversão alimentar e na taxa de eficiência protéica obtida nos peixes alimentados com as dietas com 0,21 e 0,71\% de fósforo provavelmente estão relacionados à pior relação cálcio:fósforo. A adequada relação cálcio:fósforo disponível é fundamental para o adequado crescimento e a retenção de minerais por tilápiasdo-nilo (Miranda et al., 2000).

Considerando o valor de fósforo disponível estimado para máximo ganho de peso, obteve-se relação cálcio:fósforo disponível de aproximadamente 1,7:1, próxima à recomendada para aves e suínos (Rostagno et al., 2005), mas diferente dos valores recomendados por Miranda et al. (2000), de 1:1 a 1:1,5, para juvenis de tilápia-do-nilo. As diferenças nos resultados obtidos por esses autores estão relacionadas aos valores de cálcio e fósforo disponíveis e pelas relações entre cálcio e fósforo nas dietas.

Os níveis de fósforo disponível que proporcionaram os melhores resultados de ganho de peso e conversão alimentar neste estudo foram superiores aos encontrados por Haylor et al. (1998) com tilápias-do-nilo e tilápia-azul (Oreochromis aureus), de 0,46 e 0,50\%, respectivamente, na MS. Valores superiores aos encontrados neste estudo foram obtidos por Borlongan \& Satoh (2001), Oliva-Teles \& Pimentel-Rodriguez (2004), Zhang et al. (2006) e Yang et al. (2006), com juvenis de milkfish (Chanos chanos), seabass Europeu (Dicentrarchus labrax), seabass japonês (Lateolabrax japonicus) e perca prateada (Bidyanus bidyanus), de 0,$85 ; 0,7 ; 0,65$ e $0,68 \%$, respectivamente, na MS. Por outro lado, Eya \& Lovell (1997) não observaram efeitos da utilização de dietas com 0,20; 0,27; 0,36; 0,44 e 0,60\% de fósforo disponível, na MS, para juvenis de bagredo-canal sobre o ganho de peso e a conversão alimentar.
A relação entre o nível de fósforo na dieta e a utilização da fração nitrogendada é bastante variável. Trabalhos conduzidos por Pimentel-Rodrigues \& Oliva-Teles (2001) e Oliva-Teles \& Pimentel Rodrigues (2004) comprovam que a utilização do nitrogênio foi mais eficiente nos peixes alimentados com dietas com 0,75 e 0,65\% de fósforo total (base em MS), respectivamente. Segundo Onishi et al. (1982), a menor utilização da proteína pelos peixes alimentados com a dieta com baixo nível de fósforo decorre da inadequada utilização dos aminoácidos derivados da proteína da dieta, que não foram utilizados para a síntese corporal, mas para a produção de energia via gliconeogênese, o que pode explicar a maior taxa de eficiência protéica pelos peixes alimentados com a dieta com 0,52\% de fósforo disponível (base em matéria natural) encontrada neste estudo.

Não foram observadas diferenças na utilização de dietas com diferentes níveis de fósforo disponível sobre os teores de água, proteína bruta e extrato etéreo e cinzas na carcaça (Tabela 3). Os resultados da fração lipídica diferem dos obtidos por Zhang et al. (2006) com a perca prata. Esses autores observaram redução linear nos teores de lipídios na carcaça com o aumento nos teores de fósforo disponível na dieta ( 0,3 a 1,3\%), resultado que também foi obtido por Yang et al. (2006), em estudo realizado com o seabass japonês.

Os resultados de proteína e gordura na carcaça diferem dos descritos por Lall (2002), que citou que a menor deposição de proteína e a maior deposição de lipídios na carcaça dos peixes alimentados com a dieta com menor valor de fósforo disponível estão relacionadas à inibição do ciclo do ácido cítrico e ao acúmulo de acetil-CoA, que promove inibição da ß-oxidação dos ácidos graxos para permitir a utilização de lipídios como fonte de energia. Assim, os peixes utilizam a proteína como fonte alternativa de energia.

Observou-se efeito quadrático $(\mathrm{P}<0,05)$ dos níveis de fósforo disponível sobre os teores de cálcio nos ossos, que foram maiores no osso opercular, com $0,60 \%$ de fósforo disponível (0,68\% na matéria natural). Para a retenção de fósforo no osso opercular, o melhor modelo de deposição foi obtido pelo método Broken-line, em que inicialmente foi observado aumento linear na deposição de fósforo no osso opercular até o nível de 0,64\% de fósforo na dieta, estimado em $8,22 \%$. Não houve aumento na deposição desse mineral quando fornecidos valores superiores de fósforo disponível nas dietas.

Para determinação das exigências de fósforo, énecessária a determinação do fósforo disponível das dietas a serem oferecidas aos peixes, considerando as diferenças entre espécies e idade para utilização do mineral e as possíveis 
Tabela 3 - Composição química da carcaça e de cálcio e fósforo no osso opercular de juvenis de tilápia-do-nilo alimentados com dietas contendo diferentes níveis de fósforo disponível

\begin{tabular}{|c|c|c|c|c|c|}
\hline \multirow[b]{2}{*}{ Variável } & \multicolumn{4}{|c|}{ Fósforo disponível (\%) } & \multirow[b]{2}{*}{ CV $(\%$} \\
\hline & 0,21 & 0,40 & 0,56 & 0,71 & \\
\hline \multicolumn{6}{|l|}{ Carcaça } \\
\hline Água (\%) & 74,05 & 71,78 & 73,63 & 72,92 & 1,17 \\
\hline Proteína bruta (\%) & 18,17 & 19,89 & 18,18 & 18,94 & 6,05 \\
\hline Extrato etéreo (\%) & 3,32 & 3,89 & 3,28 & 3,46 & 8,68 \\
\hline Cinzas (\%) & 4,75 & 4,19 & 4,79 & 4,00 & 15,51 \\
\hline \multicolumn{6}{|l|}{ Osso } \\
\hline Cálcio ${ }^{2}$ & 15,30 & 17,94 & 19,99 & 18,94 & 2,12 \\
\hline Fósforo ${ }^{3}$ & 5,731 & 6,718 & 7,904 & 8,258 & 2,06 \\
\hline
\end{tabular}

${ }^{1} \mathrm{CV}=$ coeficiente de variação.

2 Efeito quadrático $(P<0,05)$ : cálcio $\left.Y=9,138+34,862 X-29,286 X^{2} ; R^{2}=0,96\right)$.

${ }^{3}$ Broken-line $(P<0,05): Y=4,4664+5,820 X ; R^{2}=0,96 ;$ fósforo disponível na dieta $=0,64 \%$; fósforo no osso = 8,22\%

interações dos nutrientes. Em dietas práticas, entre os fatores antinutricionais, destaca-se o ácido fítico, que afeta a digestibilidade da proteína (aminoácidos) e a disponibilidade de diversos nutrientes.

As diferenças nas exigências de fósforo disponível obtidas por esses autores estão relacionadas à espécie de peixe utilizada, à fonte de fósforo, ao tamanho do peixe, ao manejo alimentar, aos minerais dissolvidos no meio aquático, à variável utilizada como critério de resposta e ao modelo estatístico utilizado.

Os resultados deste estudo indicam que o adequado nível de fósforo disponível em dietas para tilápias-do-nilo é necessário para o crescimento, a utilização de nutrientes e a deposição de minerais nos ossos de juvenis desta espécie. Além disso, a determinação da exigência de fósforo é necessária para aumentar o desempenho produtivo dos peixes e diminuir sua excreção no meio aquático.

\section{Conclusões}

A exigência de fósforo disponível para juvenis de tilápia-do-nilo é de 0,52\%, equivalente a 0,59\% de fósforo disponível na matéria seca.

\section{Literatura Citada}

ASGARD, T.; SHEARER K.D. Dietary phosphorus requeriment of juvenile Atlantic salmon, Salmo salar L. Aquaculture Nutrition, v.3. p.17-23, 1997.

BAEVERFJORD, G.; ASGARD, T.; SHEARER, K.D. Development and detection of phosphorus deficiency in Atlantic salmon, Salmo salar L., parr and post-smolts. Aquaculture Nutrition, v.4, p.1-11, 1998.

BORLONGAN, I.G.; SATOH, S. Dietary phosphorus requeriment of juvenile milkfish, Chanos chanos (Forsskal). Aquaculture Research, v.32, p.26-32, 2001.
BREMER-NETO, H.; GRANER, C.A.F.; PEZZATO, L.E. et al. The spectrophotometric method on the routine of 1,5diphenylcarbazide was adjusted on chromium determination in feces, alter its utilization as a biological marker as chromium (III) oxide. Ciência Rural, v.25, n.3, p.691-697, 2005.

CHENG, A.C.; WU, J.D.; YANG, S.D. et al. Dietary phosphorus requeriment of juvenile Malabar grouper (Epinephelus malabaricus). Journal of Fish Society Taiwan, v.32, p.41-52, 2005.

DOUGALL, D.S.; WOODS, L.C.; DOUGLASS, L.W. et al. Dietary phosphorus requirements of juvenile striped bass, Morone saxatilis. Journal of World Aquaculture Society, v.27, p.8291, 1996.

EYA, J.C.; LOVELL, R.T. Available phosphorus requirements of food-size channel "catfish" (Ictalurus punctatus) fed practical diets in ponds. Aquaculture, v.154, p.283-291, 1997.

FURUYA, W.M.; GONÇALVES, G.S.; FURUYA, V.R.B. et al. Fitase na alimentação da tilápia do Nilo (Oreochromis niloticus L.): desempenho e digestibilidade. Revista Brasileira de Zootecnia, v.30, n.3, p.924-929, 2001b.

FURUYA, W.M.; PEZZATO, L.E.; MIRANDA, E.C. et al. Coeficientes de digestibilidade aparente da energia e nutrientes de alguns ingredientes pela tilápia do Nilo, Oreochromis niloticus (L.) (linhagem tailandesa). Acta Scientiarum, v.23, n.2, p.465-469, 2001a.

HARDY, R.W.; GATLIN, D.M. Nutritional strategies to reduce nutrients losses in intensive aquaculture. In: SIMPOSIUM INTERNACIONAL DE NUTRICIÓN ACUÍCOLA, 6., 2002, Cancun. Memórias... Cancun: 2002. p.23-34.

HAYLOR, G.S.; BEVERIDGE, M.C.M.; JAUNCEY, K. Phosphorus nutrition of juvenile Oreochromis niloticus. In: INTERNATIONAL SYMPOSIUM ON TILAPIA, 2., 1998, Manila. Proceedings... Manila: International Center for Living Aquatic Resources Management, 1998. p.341-345.

LALL, S.P. The minerals. In: HALVER, J.E.; HARDY, R.W. (Eds.). Fish nutrition. 3.ed. San Diego: Academic Press, 2002. p. 260-308.

LOVELL, R.T. Nutrition and feeding of fish. New York: Van Nostrand Reinhold, 1988. 260p.

MIRANDA, E.C.; PEZZATO, A.C.; PEZZATO, L.E. et al. Relação calcio/fósforo disponível em rações para tilápia do Nilo (Oreochromis niloticus). Revista Brasileira de Zootecnia, v.29, n.6., p.2162-2171, 2000.

NATIONAL RESEARCH COUNCIL - NRC. Nutritional requirements of fishes. Washington, D.C.: Academic Press, 1993. 114p.

NOSE, T. On the digestion of food protein by gold-fish (Carassius auratus L.) and rainbow trout (Salmo irideus G.). Bulletin Freshwater Fisheries Research Laboratory, v.10, p.11-22, 1960. 
OLIVA-TELES, O.; PIMENTEL-RODRIGUES, A.M.P. Phosphorus requirements of European sea bass (Dicentrarchus labrax L.) juveniles. Aquaculture Research, v.35, p.636-642, 2004.

ONISHI, T.; SUZUKI, M.; TAKEUCHI, M. Change in carp hepatopancreatic enzyme activities with dietary phosphorus levels. Bulletin of Japanese Society of Science and Fisheries, v.47, p.353-357, 1982.

PEZZATO, L.E.; MIRANDA, E.C.; PEZZATO, A.C. et al. Digestibilidade aparente de ingredientes pela tilápia do Nilo (Oreochromis niloticus). Revista Brasileira de Zootecnia, v.31, n.4, p.1595-1604, 2002.

PIMENTEL-RODRIGUES, P.; OLIVA-TELES, O. Phosphorus requeriments of gilthead sea bream (Sparus aurata L.) juveniles. Aquaculture Research, v.32, p.157-161, 2001.

RICHIE, M.; BROWN, P.B. Availability of phosphorus from feedstuffs fed to rainbow trout, Oncorhynchus mykiss. Aquaculture, v.142, p.269-282, 1996.

ROSTAGNO H.S.; DONZELE, J.L.; GOMES, P.C. et al. Tabelas brasileiras para aves e suínos: composição de alimentos e exigências nutricionais. 2.ed. Viçosa, MG: Editora UFV, 2005. 186p.
ROY, P.K.; LALL, S.P. Dietary phosphorus requirement of juvenile haddock (Melanogrammus aeglefinus L.). Aquaculture, v.221, n.1-4, p.451-468, 2003.

STATISTICAL ANALYSIS SYSTEM - SAS. SAS/STAT: user's guide. Version 6, 12.ed. Cary: 2000. (CD-ROM).

SILVA, D.J.; QUEIROZ, A.C. Análise de alimentos: métodos químicos e biológicos. 3.ed. Viçosa, MG: Editora UFV, 2002. 235p.

SUGIURA, S.H.; HARDY, R.W.; ROBERTS, R.J. The pathology of phosphorus deficiency in fish - a review. Journal of Fish Disease, v.27, p.255-265, 2004.

Van der PLOEG, M.; BOYD, C.E. Geosmin production by cyanobacteria (blue green algae) in fish ponds at Auburn, Alabama. Journal of the World Aquaculture Society, v.22, p.207-216, 1991.

YANG, S.; LIN, T.; LIU, F. et al. Influence of dietary phosphorus levels on growth, metabolic response and body composition of juvenile silver perch (Bidyanus bidyanus). Aquaculture, v.253, p.592-601, 2006.

ZHANG, C.; MAI, K.; AI, Q. et al. Dietary phosphorus requeriment of juvenile Japanese seabass, Lateolabrax japonicus. Aquaculture, v.255, p.201-209, 2006. 